\title{
Computer-assisted audit techniques: classification and implementation by auditor ${ }^{* *}$
}

\author{
Yuliya Serpeninova ${ }^{1}$, Serhii Makarenko ${ }^{2 *}$, Marina Litvinova ${ }^{3}$ \\ ${ }^{1}$ Associate Professor at the Accounting and Taxation department, \\ ${ }^{2}$ Postgraduate student at the Economic Cybernetics Department, \\ ${ }^{3}$ Master student \\ Sumy State University
}

JEL Classification: $M$ 40, M 41

\begin{abstract}
The article deals with the main issues in classification of information technology (IT) in auditing and computer-assisted audit techniques (CAATs) adoption by the auditors during audit process organization. Among these issues, authors underline CAATs adoption, which varied by firm size. There is a strict connection between auditor's firm size and degree of technologies advances. The most used types of CAATs and IT were generalized, they are: audit software, Electronic Spreadsheets, Electronic Working Papers. Besides these technologies, auditors can often use a program language to gain access to data and manipulate this data. Utility software and specialized audit software (Statistical Software, Test Data, Database SQL Search, Parallel Simulation Software, Embedded Audit Modules) is highly used to perform specific auditor task or facilitate solving a set of audit function performing. To increase audit technology acceptance among audit companies, the technological, organizational and environmental aspects that influence the adoption need to be improved.
\end{abstract}

Keywords: audit; information technology in audit; computer-assisted audit techniques.

Corresponding author:

${ }^{1}$ E-mail address: y.serpenynova@uabs.sumdu.edu.ua

ORCID ID: 0000-0002-4448-3484

${ }^{2}$ E-mail address: s.makarenko@i.ua

ORCID ID: 0000-0001-6455-3585

${ }^{*}$ The research was conducted within the framework of the scientific-applied theme: «Corporate social and environmental responsibility for sustainable development: stakeholders partnership in the real, financial and public sectors of the economy» (0117U003933).

${ }^{3}$ E-mail address: kotepopolski@gmail.com

(C) 2020 Y.Serpeninova, S.Makarenko, M.Litvinova

doi: https://doi.org/10.26642/ppa-2020-1-44-49 


\section{Introduction}

In fast world of technologies, it is impossible for accountants and auditors to use only on information gathered from traditional papers to render competitive services and issue the appropriate opinion on financial reporting.

Many organizations have opted to utilize sophisticated information technologies for developing their business process support as well as improving their information processing activities. This increases the need for IT and CAATs to admit auditors to proceed to be able to comply their review and monitoring tasks effectively, as well as to play key roles in the cause of innovation in these businesses more generally.

Over the past few years, the number of employees who have never experienced advanced audit methods has been reduced. This phenomenon continues to gain popularity and has many advantages, such as cost effectiveness, maintaining of test specific risks, effective use of time. CAATs help to avoid fraud through database analysis and do all auditors work in a single database.

Despite the high costs of implementing CAATs, costs for the work of the entire audit activity of the company are reduced by increasing productivity and reducing the number of errors in the audit process.

Nowadays, a fairly wide range of software has been invented for specific tasks. For example, one software was created in order to exist an audit in certain industries and with a certain set of audit procedures, the other - more extensive use and is used so that a large number of clients (the same employees of the company) can use them.

Urgent task in this context is to review current type of IT and CAATs usage and their application in audit practice.

\section{Literature review}

Each company select the accounting organization method of transaction recording, otherwise it is commonly required that organizations have to reveal certain financial and administration information to the government and public usages; and because accounting is an indispensable instrument in business resolution making-process [2]. Bala said that the growth of the cultivation of information technologies was originated by computer products, such as software that make accounting easiness for clients of accounting content [25].

In foretime, auditors' computer skills were limited to auditing near the computer (printing and scrutinizing the information) and using the computer as an administrative instrument. The fast up growth in data contents has increased the necessity for auditors to alter their audit advance by involving powerful software applications in the realization of the audit. In accordance with Gelinas, Davis and Knechel, software appliques are widely utilized by auditors and it is essential for potential auditors (auditing students) to get the obligatory exposure [7].

Veerankutty resolutes IT Auditing like a technique of collective and estimating argument to determine if a computer organization has been designed for supporting data wholeness, protecting assets, admitting organizational aims to be accomplished strategically, and using resources efficiently [16].

Nearon, another thinker on the topic of computers in auditing is convinced that effective auditing, through the proper usage of computerized organizations, will reduce the expenses of capital for organizations, leading to bulky return on injections. This has benefits for the public [21].

Otherwise, auditing, in the sense of Gelinas, is a logical process, and the auditor has to rely on his/her judgment, current trends in audit and changing from overly structured methods, to a much more subjective, empiric approach in which the auditor's judgment is even more proved than before [7]. More or less methods utilized by auditors in this modern approach cover standardized audit platforms, statistical sampling methods, regression analysis, and models for evaluating internal control, resolution aids and expert organizations. These normally time-consuming techniques are becoming an integral part of each audit. In modern auditing, computer technology forms the basis on which auditors' function, said Knechel [7]. Thereof it is critical that the skills needed to function in a computerized environment be incorporated into auditing educational activity [7].

Companies are relying severely on IT in conducting their workaday actions, resulting in alters in the disposition of the operation and the business partnership. This is coupled by the broadened of internet, valid - time accounting organizations, electronic commerce (e - commerce) and using portal sites and social media to reveal financial information. Consequently, Kotb and Roberts noticed that this guides to an increasing requires for new IT audit techniques [15].

Also, higher quality audit is not just one motivate for auditing firms to assume IT in the audit cause. Former investigation has exerted to originate models to clarify and predict the success of the admission and assume of new technologies. For instance, Bierstaker modified the Unified Theory of Acceptance and Assume of Technology (UTAUT), originated by Venkatesh, with audit background [11]. They propose four key determinants that influence on the election of technology: consumer expectations about organization performance; consumer self-awareness of the effort required to utilize the new substructure; consumer perceptual experience of the role of influencers in promoting organization usage; and consumer expectations after the presence of an suitable infrastructure to maintain the usage of the substructure.

In keeping with Ismail and Abidin, the degree of IT experience among auditors is shorter than their perception of the magnitude of audit technology [10]. Therefore, we inspect the usage and seriousness of audit technology in the technical and managerial operations of the auditing process, as perceived by an auditor.

Janvrin and Bierstaker in their papers said, that the complication of the customer's IT organization influences the disposition of the test check form chosen [12]. In the frame of reference of complication, where auditors rely on control, auditors are more likely to usage IT in auditing operations. According to Janvrin, the usage of audit technology in audit operations changes by firm bigness [12]. 
Sundgren and Svanström argue that audit quality is relatively lower in non-Big 4 companies [24]. This is mostly 'cause the auditor depends on fees from a single fundamental customer and negatively influences the property of the audit noticed Craswell[5]. Dissimilarity in the quality of audits by firm bigness vis-a-vis the decision that Big 4's big firms may have reputational losses due to their investment in technology and capital. Ismail and Abidin found that the auditors of the four major companies rated their overall IT knowledge better than the auditors of non-Big 4 firms [10]. Venkatesh et al. inspected the behavior of junior and senior workers, which utilize a usage of the newest technologies [25]. Likewise, Gambatese and Hadmitell conclude that efficient managerial support enables innovation performance [4]. Abou-El-Sood initiated and used qualitative and quantitative inspect to originate and validate a measurement technology scale including the following: firm/auditor against reception usage audit technology in technical audit operations; auditing characteristics compared to determinants influencing the usage of audit technologies in the auditing procedure; consequences of usage audit technology within the audit procedure [1].

Besides, former study analyses the election of audit technology through the perspective of peculiar auditors (Janvrin, Bierstaker, \& Lowe) [12]. Auditing is likewise pressured with the obligation to avoid audit gap [3]. If the number of audit days growths, then the quality of financial reporting would be jeopardized otherwise organization cannot provide timely information to their investors (Mohamad-Nor, Shafie and Wan-Hussin) [20]. Therefore, audit labor must be performed quickly, efficiently and effectively. Whereas, the significance of audit technology is widely accepted by the professional accounting authority and audit companies, in practice the audit technology performance is not widespread among public accounting firms (Curtis \& Payne) [6].

Many foregoing writings observed the performance of technology in audit occupation, centering on auditing job whereabouts the technology was used by auditors in private organizations and open organizations (Huang, Hung, \& Tsao; Mahzan\&Lymer; Kim, Mannino, \& Nieschwietz; Moorthy et al.; Ramamoorthi\&Weindenmeer; Mahzan et al.) [8, 14, 18]. Despite the broad utilization of audit technology in auditing (Mahzan and Lymer) and the validity of audit technology (Ismail), such utilization is not voluminous among open accounting companies specifically in presenting outside audit of their business customers (Curtis \& Payne) [6].

\section{The identification of previously unresolved issues and the formulation of research hypotheses}

Various methodologies of scientists to designate the conception of IT audit, its role and need in the practitioner field of bookkeepers and auditors were considered. Cleverness this locality will facilitate the work of professionals and make it more multifaceted and effective in a rapidly originating environment.

But among unresolved issues we faced with absence of clear understanding of role IT and CAATs in auditors' work, main issues in their implementation by different auditor firm and categories of CAATs in accordance with specific goals.

Purpose of the article was defined as analysis of main categories of CAAT and IT implementation and application by an auditor in practice.

\section{Research methodology and methods}

Research methodology contains a comparative analysis, synthesis, statistical and graphical methods, which gives the wide picture of different CAATs usage by the auditors all over the world and allows to stress the main peculiarities in such usage.

\section{Main results}

Today auditors work constantly with computerized records. It is likely that many audit clients have eliminated or will eliminate a substantial portion of their paper documents and replace them with electronic documents filed only in computerized form. An auditor who is unable to use computerized audit tools effectively will be at a tremendous weakness. Therefore, today's auditor must be equipped with the understanding of alternative instruments and approaches to test the operations of computerized systems and gather and evaluate data contained in computerized records.

Computer audit software, known as Generalized Audit Programs (GAS) which are readily accessible and do not require for much expertise from the auditor can be used [4]. Generalized audit software is the finished software that offers a means to gain access to and manipulate data maintained on computer storage media. This software has all the characteristics of mathematical computations, stratification, statistical analysis, sequence check, duplicate check, re-computations, etc [23]. Auditors can obtain confirmation directly on the quality of the records produced and maintained by application systems. In turn, their conclusions on the quality of the records will enable them to make judgments about the quality of application system that processes these records. GAS cannot perform the audit but can facilitate selection and processing the information as per the clients' requirements. The two most commonly used GAS are ACL (Audit Command Language) and IDEA (Interactive Data Extraction Analysis) [4]. Some of the products of generalized audit software related to query and analysis are pointed in Table 1.

Besides generalized audit software, auditors can often use a program language to gain access to data and manipulate this data. In particular, many auditors use programming languages, such as C, C++, JAVA, SQL, Pyton, PHP, and generalized statistical software, such as ACL and IDEA, to collect evidence on system reliability. Some of the general support tools are: MS Office, Oracle, Webmetrics 3.0, Access, Excel etc [13]. 
Table 1

Query and Analysis Tools

\begin{tabular}{ll}
\hline Product & Features \\
\hline Access & A database program that provides data selection, analysis, and reporting. \\
ACL & General audit software that reads files from most formats (e.g. EBCDIC, TXT) and \\
provides data selection, analysis, and reporting. \\
Excel & Spreadsheet software that provides analysis, calculation, graphing, and reporting. \\
CA-Examine & A programming language that provides data selection, analysis, and reporting. \\
CA-Easytrieve & A programming language that provides data selection, analysis, and reporting. \\
C, C++, JAVA, SQL, Pyton, PHP & A programming language that provides data selection, analysis, and reporting. \\
SAS, SPSS & A programming language that provides data selection, analysis, and reporting. \\
\hline
\end{tabular}

Program languages havebeen proved to be useful to auditors' work for several reasons.

First, most functions incorporated within generalized audit software are included within program languages. For example, auditors can use fourth - generation languages to select data from files that satisfy certain criteria and to format this data for reporting purposes. They might have weaker capabilities in certain few areas - for example, statistical sampling capabilities. Often auditors can overcome these difficulties, however, by using «macros», which allow them to write programs to perform particular functions and then to invoke these programs with a single command.

Second, for the types of functions auditors might want to perform, fourth generation languages could be more user friendly than generalized audit software. For example, a program language might provide then with more flexible reporting capabilities [16]. Auditors might be able to avoid difficult downloading of data from one computer to another computer or troublesome conversion of one file or data format to another file or data format.

Third, if auditors use a program language that is employed extensively throughout the organization audited, they are likely to able to get good support to overcome any difficulties they might encounter. For example, if the organization uses relational database and SQL, many persons within the organization should be able to assist auditors if they have problems using SQL to access and manipulate data in the database [10].

Utility software is software that performs fairly specific functions that are needed frequently, often by a large number of users, during the operation of computer systems. For example, they include copy programs, sort programs, disk search programs, and disk formatting programs. They often come as a part of the suite of programs provided with major system software, such as operating systems, database management systems, program languages, or data communication software [13]. Much independent utility software has now been developed; however, it can be purchased to undertake functions that cannot be accomplished using the utility programs provided with system software or alternatively to undertake functions more effectively and efficiently than the utility programs provided with system software. Some exists as freeware and might be downloaded, from a site on the Internet.

Because many utility software is now available, auditors might often have difficulty identifying what software exists, where it is located, how it can be procured, and what functions it performs. Some operating system vendors have produced documentation that describes utility software that they and other organizations have developed which can assist auditors in their work. Various Usenet groups on the Internet will also provide information about utility software that might be useful [19]. It will help, if auditors understand the major types of utility software that exist so they can perhaps pinpoint better the software they need.

Specialized audit software is software written in a procedure or problem oriented language to fulfill a specific set of audit tasks. The term «specialized» does not mean the software performs only a narrow range of functions. Indeed, in some cases the software has extensive functionality. Rather, specialized means auditors have developed and implemented the software where the purposes and users of the software are well defined before the software is written. On the other hand, with generalized software, the specific tasks to be undertaken by the software and the identity of users will not be known at the outset.

One important area where auditors often have to prepare specialized audit software is in the development and implementation of concurrent auditing techniques. Concurrent auditing techniques collect audit evidence at the same time as the application system is processing production of data [19]. They require audit hooks, modules, or routines to be embedded in the application system to select the evidence required. These are often implemented via specialized program code.

Modern software greatly facilitates the work of the auditor. A wide range of software products allows for effective audit in various areas. There are no different functions that perform their products; it satisfies the needs of people who use it. Different types of programs can be combined with each other and used as separate units. Each of the programs is unique and includes a set of necessary tools for solving the problems of the industry.

Problems of accepting and application enterprise software for conducting audit treatments are one of the considerable directions of research of scientists who are investigating this problem. In an era of widespread applying of IT technologies, its application in the audit field is a very topical issue. That is why, using a diversity of statistical methods for collecting, analyzing and processing intelligence, Venkatesh and Bala [25], Ismail and Abidin [10], Mahzan [16] and other scholars, through a survey of representatives of dissimilar firms related to auditing and accounting conducted a statistical review that detects the degree of use of CAATs in these enterprises.

In these statistical research there was such structure of respondents: from small audit firms (39.5\%) and medium firms $(44.7 \%) .15 .8 \%$ of respondents were from Big 4 firms. These small, medium and big firms offered different type of auditor services i.e. financial audit $(100 \%)$, IT audit $(28.9 \%)$, internal audit $(50.0 \%)$, taxation (92.1 \%), business 
advisory $(57.9 \%)$ and financial advisory $(52.6 \%)$. Reception of audit technology was collected based on the percentage of audit issue conducted using the respective audit technology (figure 1 and 2). Consistent with Venkatesh and Bala, the percentage was used as a dimension to assess the degree of proving of audit technology acceptance [25].

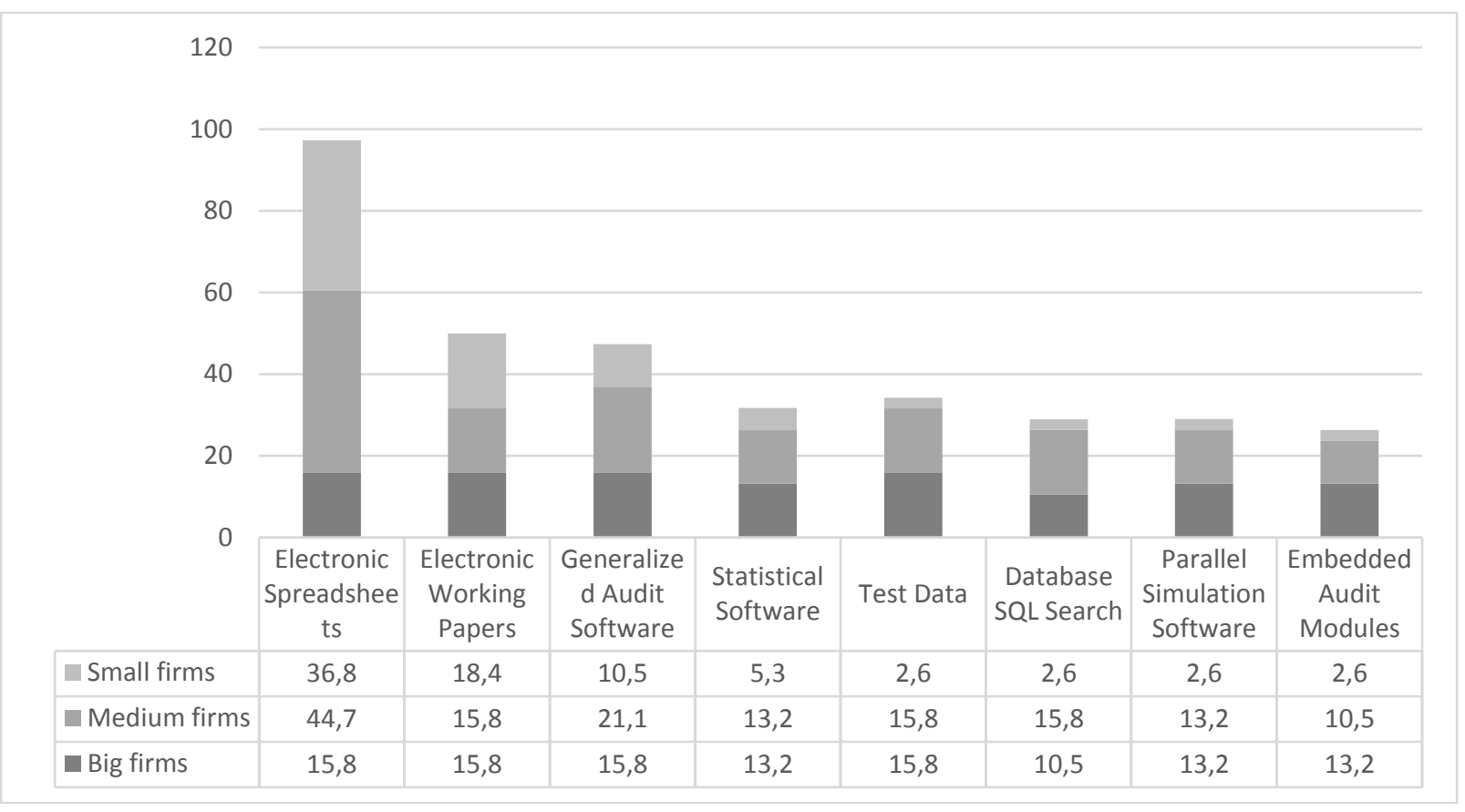

Fig. 1. Audit Technology Adoption, complied by authors according to [17].

The output results give an evidence that CAATs and IT usage varied by auditor firm size. Less progressive technologies were used by generally small and medium firms whilst the more advanced technologies were used by big audit firms. This result is appropriate with Ismail and Abidin findings [10].

In small and medium firms a high percentage of respondents $(97.3 \%)$ adopted Electronic Spreadsheets, of which $71.1 \%$ used it very extensively. Nearly half of the respondents adopted Electronic Working Papers (23.7 \% extensively assume the applique). As for Generalized Audit Software, only $47.4 \%$ of the respondents adopted it with $21.1 \%$ extensively performed their auditing performance by using the software.

Unfortunately many of the respondents had never used advanced audit techniques in performing audit tasks, i.e. Embedded Audit Modules (73.7 \%), Database SQL Search and Retrieval (71.1\%), Parallel Simulation Software (71.1 \%), Test Data $(65.8 \%)$ and Statistical Software $(68.3 \%)$ [10].

\section{Concluding remarks}

The acceptance and usage of CAATs between auditors is very momentous, because CAATs increase audit effectiveness and efficiency. Latter audit standards encourage auditors to adopt CAATs to perfect audit efficiency and effectiveness. Prior CAAT research is generally descriptive in nature. Research carried out proposes that CAATs acceptance is fairly low and differentiates among firms.

Only a limited number of scientific studies have been conducted seek to aid wider understanding of the issues of CAATs adoption. While academical research on this topic is very confined, there have been a number of surveys carried out by professional authorities to which auditors belong, outlining CAATs usage in practice across a variety of industries.

Nevertheless, CAAT is not the solution to all problems, since this area is only gaining in popularity and scope. The system requires a deeper study and consideration of all the needs of auditors, since the most popular obstacles to the implementation of CAAT are the difficulty in mastering technically complex products and requires a lot of mental effort for employees in the learning process.

Given the rapid development of the field of information technology in the coming years, auditors will not be able to carry out their activities in "manual mode».

The results of the research found that audit firms use mainly simple CAATs and IT, especially small and medium firms. There is strict connection with audit firm size and degree of technologies it used.

To increase audit technology acceptance among audit companies, the technological, organizational and environmental aspects that influence the adoption need to be improved. From the technological context, this study suggests that the audit tools should be designed to be user-friendly and less complex so that it could be easily accepted in audit firms. The reconcilability of the technology should be made clear with audit firms' existing systems and match with audit objectives that need to be accomplished. 
In the organizational context, top administration should increase their commitment and willingness to provide trainings as well as infrastructure for audit technology acceptance. With sufficient trainings and supports, employees' competency could be enhanced, and audit technology could be successfully implemented.

On top of that, audit technologies should become the main helper for practicing auditors in their professional activities. Specialists in this field must be familiar with the most popular computer tools and use them for different goals and tasks. As in environmental aspects, vendor should provide quality technical support, on-going maintenance and trainings to audit firms' employees. This study suggests that professional accounting bodies should tighten the requirements to use audit technology and give supports to encourage audit firms to increase its adoption.

\section{References:}

1. Abou-El-Sood, H., Kotb, A. and Allam, A. (2015), «Exploring auditors' perceptions of the usage and importance of audit information technology» International Journal of Auditing, Vol. 19 (3), pp. 252-266, [Online], available at: https://doi.org/10.1111/ijau.12039

2. ACL Service Ltd, [Online], available at: http://www.acl.com/solutions/audit.aspx

3. Afify, H.A.E. (2009), «Does implementing corporate governance have any impact? Empirical evidence from Egypt», Journal of Applied Accounting Research, Vol. 10 (1), pp. 56-86, [Online], available at: http://dx.doi.org/10.1108/09675420910963397

4. The Institute of Chartered Accountants of India (2009), Comprehensive Guide on Information Systems Audit, Vol. II, $2^{\text {nd }}$ ed., Committee on Information Technology, New Delhi.

5. Craswell, A., Stokes, D.J. and Laughton, J. (2002), «Auditor independence and fee dependence», Journal of Accounting and Economics, Vol. 33 (2), pp. 253-275, [Online], available at: https://doi.org/10.1016/S0165-4101(02)00044-7

6. Curtis, M.B. and Payne, E.A. (2008), «An examination of contextual factors and individual characteristics affecting technology implementation decisions in auditing», International Journal of Accounting Information Systems, Vol. 9 (2), pp. 104-121, [Online], available at: http://dx.doi.org/10.1016/j.accinf.2007.10.002

7. Gelinas, Davis, Knechel (2014), Business processes and information technology, Mason, OH: South-Western.

8. Huang, S.M., Hung, Y.C. and Tsao, H. H. (2008), «Examining the determinants of computer-assisted audit techniques acceptance from internal auditors' viewpoints», International Journal of Services and Standards, Vol. 4 (4), pp. 377-392, [Online], available at: http://dx.doi.org/10.1504/IJSS.2008.020054

9. Hunton, J. and Rose, J.M. (2010), « $21^{\text {st }}$ century auditing: advancing decision support systems to achieve continuous auditing», Accounting Horizons American Accounting Association, Vol. 24, No. 2, pp. 297-312, [Online], available at: https://doi.org/10.2308/acch.2010.24.2.297

10. Ismail, N.A. and Abidin, A.Z. (2009), «Perception towards the importance and knowledge of information technology among auditors in Malaysia», Journal of Accounting and Taxation, Vol. 1 (4), pp. 61-69.

11. Janvrin, D., Bierstaker, J. and Lowe, J. (2009), «An investigation of factors influencing the use of computer-related audit procedures», Journal of Information Systems, Vol. 23, No. 1, pp. 97-118, [Online], available at: https://doi.org/10.2308/jis.2009.23.1.97

12. Janvrin, D., Bierstaker, J., and Love, D. (2008), «An examination of audit information technology use and perceived importance», Accounting Horizons, Vol. 22 (1), pp. 1-21, [Online], available at: https://doi.org/10.2308/acch.2008.22.1.1

13. Janvrin, J. and Wood, A. (2016), «Editorial: the Journal of Information Systems 2015 conference on information technology audit», Journal of Information Systems, Vol. 30, No. 1, pp. 3-5, [Online], available at: https://doi.org/10.2308/isys-10483

14. Kim, H.J., Mannino, M., and Nieschwietz, R.J. (2009), «Information technology acceptance in the internal audit profession: Impact of technology features and complexity», International Journal of Accounting Information Systems, No. 10, pp. 214-228, [Online], available at: https://doi.org/10.1016/j.accinf.2009.09.001

15. Kotb, A. and Roberts, C. (2011), «The impact of E-business on the audit process: An investigation of the factors leading to change», International Journal of Auditing, No. 15, pp. 150-175, [Online], available at: https://doi.org/10.1111/j.1099-1123.2011.00427.x

16. Mahzan N. and Veerankutty F. (2011), «IT Auditing Activities of Public Sector Auditors in Malaysia African», Journal of Business Management, Vol. 5(5), pp. 1551-1563.

17. Mahzan, N. and Lymer, A. (2009), «Examining adoption of computer assisted audit tools and techniques (CAATTs) by internal auditors: Cases of UK internal auditors», In Proceedings of 12th International Business Information Management Association (IBIMA) Conference, Kuala Lumpur, Malaysia, pp.1-46.

18. Mahzan, N., Muhammad, R., Shahimi, S., Yahya, Y. and Ahmad Radzi, N. (2009), 2008 survey report on CAATTs usage by internal auditors in Malaysia, Keeping in Touch, Institute of Internal Auditors, Malaysia.

19. Malaescu, I. and Sutton, G. (2015), «The reliance of external auditors on internal audit's use of continuous audit», Journal of Information Systems, Vol. 29, Issue 1, pp. 95-114, [Online], available at: https://doi.org/10.2308/isys-50899

20. Mohamad-Nor, M.N., Shafie, R., and Wan-Hussin, W.N. (2010), «Corporate governance and audit report lag in Malaysia», Asian Academy of Management Journal of Accounting and Finance, Vol. 6 (2), pp. 57-84.

21. Moorthy, M.K., Seetharaman, A., Mohamed, Z., Gopalan, M. and San, L.H. (2011), «The impact of information technology on internal auditing», African Journal of Business Management, Vol. 5 (9), pp. 3523-3539.

22. Ramamoorthi and Weindenmeer (2004), «Chapter 9:The pervasive impact of information technology on internal auditing», Institute of Internal Auditors Inc, pp. 301-377.

23. Sandra Senft and Frederick Gallegos, (2009), Information Technology Control an Audit, $3^{\text {rd }}$. ed., CRC Press, Auerbach Publications.

24. Sundgren, S. and Svanström, T. (2010), «Auditor-In-Charge Characteristics and Going Concern Reporting Behavior: Does number of assignments, age and client fee dependence matter», Contemporary Accounting Research, Vol. 31(2), pp. 531-550, [Online], available at: https://doi.org/10.1111/1911-3846.12035

25. Venkatesh, V. and Bala, H. (2012), Adoption and impacts of interorganizational business process standards: Role of partnering synergy, Information Systems Research, pp. 1-27.

26. Young, R. and Jordan, E. (2008), «Top management support: Mantra or necessity», International Journal of Project Management, Vol. 26 (7), pp. 713-725, [Online], available at: https://doi.org/10.1016/j.ijproman.2008.06.001

\footnotetext{
${ }^{* *}$ How to cite this article: Serpeninova Y., Makarenko S., Litvinova M. Computer-assisted audit techniques: classification and implementation by auditors. Public Policy and Accounting. 2020, Vol. 1. https://doi.org/10.26642/ppa-2020-1-44-49
} 